\title{
Heterotopic Ossification in Vertebral Interlaminar/Interspinous Instrumentation: Report of a Case
}

\author{
Giuseppe Maida, Eleonora Marcati, and Silvio Sarubbo \\ Division of Neurosurgery, Department of Neuroscience and Rehabilitation, University-Hospital S. Anna, 8 Via Aldo Moro, \\ 44124 Ferrara, Italy \\ Correspondence should be addressed to Giuseppe Maida, giuma@vodafone.it
}

Received 2 April 2012; Accepted 21 June 2012

Academic Editors: A. E. Beris, Y. Kato, and Y. Kawaguchi

Copyright (C 2012 Giuseppe Maida et al. This is an open access article distributed under the Creative Commons Attribution License, which permits unrestricted use, distribution, and reproduction in any medium, provided the original work is properly cited.

\begin{abstract}
We present here a rare case of heterotopic ossification in interspinous/interlaminar Coflex device. The classical surgical indications for these implants are degenerative canal stenosis, discogenic low back pain, disk herniations, facet syndrome, and instability. However, fractures of spinous processes are a potential risk after interspinous/interlaminar devices' implantation. Recently, heterotopic ossification, a well-known complication of hip and knee arthroplasty, has been reported after cervical and lumbar prosthesis. We performed undercutting and implantation of the dynamic interspinous/interlaminar device to treat an adult male patient with L4-L5 stenosis. The patient underwent 45-day imaging and clinical followup, and we observed both a neurological and imaging improvement. A CT bone scan, performed 3 years after surgery for recurrence of neurogenic claudication, showed a new stenosis due to an abnormal ossification all over the device. To our knowledge, this is the first reported case of heterotopic ossification in an interspinous/interlaminar dynamic device. Accordingly, we aim to suggest it as a new complication of interspinous/interlaminar devices.
\end{abstract}

\section{Introduction}

Heterotopic ossification ( $\mathrm{HO}$ ) was defined as an abnormal formation of bone within extraskeletal soft tissues $[1,2]$. The pathogenesis of $\mathrm{HO}$ is unknown, and it is most commonly seen following total hip and knee arthroplasty [39], however, it is also reported in total disc arthroplasties, more frequently in the cervical region [10-20].

We present here what is, to our knowledge, the first reported case of HO secondary to an interspinous/interlaminar dynamic device (Coflex) in an adult male.

\section{Case Report}

2.1. History and Examination. This 58 years-old man presented with a 6-month history of progressively worsening low back pain. The intensity of pain, assessed by using the visual analogue scale (VAS), was scored at $8 / 10$. His pain was radiating to legs and impairing deambulation. His medical history was significant for hypertension. In 2008, the patient underwent microsurgical decompressive undercutting and implantation of an interspinous/interlaminar Coflex device because of L4-L5 stenosis (as documented by MRI). Postoperative and 45-day follow-up radiographic images ensured proper device position and maintenance of the range of motion. On postoperative and 45-day followup examination, the patient showed a quite total resolution of the prior clinic (VAS 3/10). In 2011, the patient came to our attention for recurrence of motor weakness with the L5 myotome affected, decreased Achilles and patellar reflexes, and neurogenic claudication. The X-rays, CT scan with bone windows (Figure 1), and MR images revealed a mature ossification of the device with relevant restenosis. Because of the patient's disabling neurological symptoms, it was felt appropriate to treat it surgically.

2.2. Operative Technique. The patient was placed in a kneechest position. A midline incision was then made and soft tissue was accordingly dissected free from the bone 


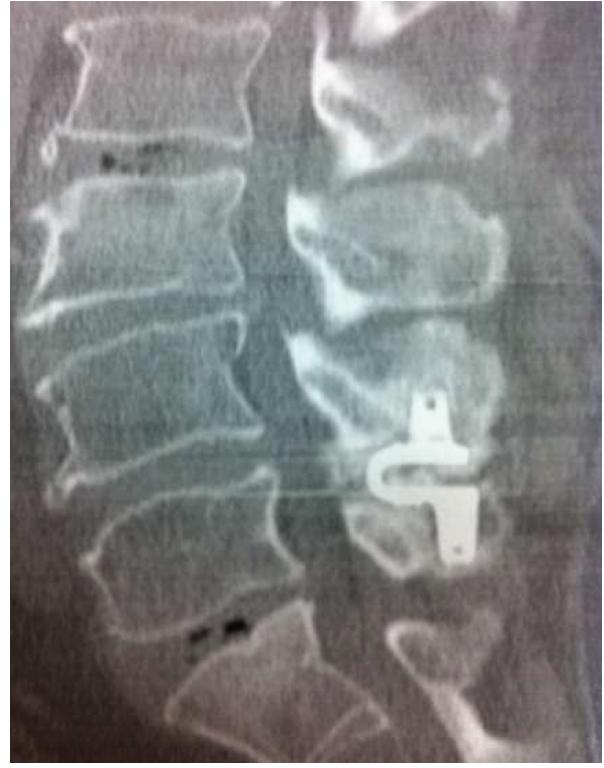

(a)

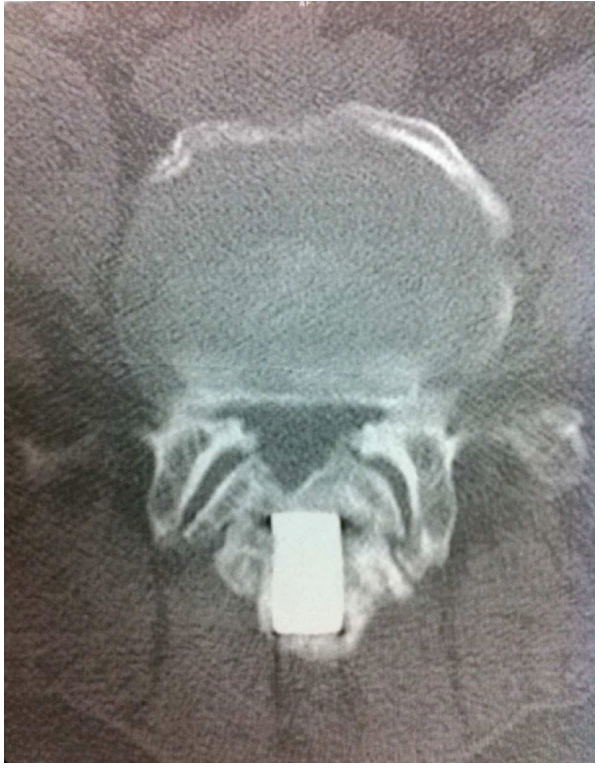

(b)

FIGURE 1: Preoperative CT bone scan showing heterotopic ossification of interspinous/interlaminar Coflex device.

in a subperiosteal fashion down to the laminae, on both sides. An abnormal osseous tuberosity was subsequently detected surrounding the L4 and L5 spinous processes. The interspinous/interlaminar Coflex device implanted at that level was not detectable, as also visible in Figure 1. Hence, we started to resect the new bone formation with a chisel. The "U-shaped" part of the device was completely filled by bone. Therefore, we proceeded the resection till the device was free to be removed. In addition, the dura mater was all covered by interlaminar bone which was consequently removed by using Kerrison rongeurs. Finally, gross-total resection of the new bone formation was achieved. Moreover, L4-L5 laminectomy with facet joints preservation and L3, S1 undercutting were performed. Then, secure haemostasis was obtained, and the wound was extensively irrigated and closed in layers.

2.3. Postoperative Course. Resection of the pathologic bone formation resulted in a rapid neurological recovery (VAS $3 / 10$ ), and the patient could then walk independently. Nonsteroidal antiinflammatory drugs were used for few weeks in the postoperative period. At the 2-month followup, the patient had a great reduction in pain and disability.

\section{Discussion}

Decompression is a widely accepted intervention for patients with lumbar canal stenosis. When associated with fusion, adjacent segment degeneration may occur. Therefore, dynamic implants like interspinous/interlaminar devices (IDs) were developed [21]. Moreover, lumbar disc rehydration was described after the implantation of posterior dynamic stabilization systems [22]. Several indications have been suggested for interspinous/interlaminar devices, ranging from treatment of degenerative canal stenosis, discogenic low back pain, disk herniations, facet syndrome, and instability [23]. Interspinous/interlaminar devices should bound spinal extension of the treated segment, relieve facet joints and low back pain, and enlarge the spinal canal at the implant level. Besides, these implants allow a less-invasive decompression with a lower rate of complications like cerebrospinal fluid fistula [24]. However, fractures of spinous processes can occur during or after interspinous spacer implants, particularly in osteopenic patients [25]. Subsidence of the implant into the bone or dislocation may also be expected [26]. In the literature, several retrospective data on biomechanic, efficacy, and complications of Coflex implants are analysed and described. However, prospective studies concern only a small population, at this time [24, 26-29].

Heterotopic ossification is a widely investigated complication following total hip and knee arthroplasty [3-9]. Recently, it has also been described for cervical [10-20] and lumbar [30,31] total disc arthroplasty [32, 33] and for posterolateral lumbar spine fusion after the use of bone morphogenetic protein-2 (BMP-2) [34, 35]. HO was defined as an unnatural formation of bone within soft tissues, juxtaposed to the skeleton, and usually not involving the periosteum $[1,2]$. HO can result in a variety of complications associated with a decline in the range of motion. It was classified into posttraumatic [36], nontraumatic or neurogenic, and myositis or fibrodysplasia ossificans progressive [1]. The pathogenesis of $\mathrm{HO}$ is unknown; an hypothesis is the imbalance in local and systemic factors inducing osteoprogenitor cells $[37,38]$. Known risk factors might be the type and size of prosthesis, operative technique, osteoarthritis, injury patterns, male gender, and age $[1,30,37]$. McAfee et al. [39] provided the first classification system of $\mathrm{HO}$ after total disc replacement by using five degrees of severity (Table 1), based on the Brooker et al. [40] total hip arthroplasty 
TABle 1: McAfee's classification of heterotopic ossification (HO).

McAfee's classification

(0) No HO

(I) Islands of bone not within the margins of the disc and not interfering with motion

(II) Bone within the margins of the disc but not blocking motion

(III) Bone within the margins of the disc and interfering with motion of the prosthesis

(IV) Bony ankylosis

* Adapted from McAfee et al. [39].

classification. McAfee's classification depends on flexionextension X-rays. Nonsteroidal antinflammatory drugs (i.e., indometacin, naproxen, diclofenac, and cyclooxygenase-2 inhibitors) and localized radiotherapy were proposed as a prophylaxis of $\mathrm{HO}$ after arthroplasty [41-43]. To treat the acute $\mathrm{HO}$, there is insufficient evidence to recommend some pharmacological agents; hence, to obtain pain relief and to improve the decreased range of motion before complications arise, clinically relevant $\mathrm{HO}$ should be resected [44]. The suggested optimal timing of surgery ranges from 12 to 18 months after radiographic evidence of $\mathrm{HO}$ maturation [1].

In our case, we chose to resect the $\mathrm{HO}$ and to enlarge the prior decompression. Patient's symptoms were quite severe, limiting his daily activities and impairing deambulation. Moreover, the relatively large size of the new bone carried potential risk of a greater neurological damage. Through posterior approach, we performed the resection of the heterotopic bone, removed the device, and achieved a greater decompression. After surgery, a prophylactic treatment with nonsteroidal antiinflammatory drugs was established to prevent the main risk of recurrence.

To our knowledge, the present is the first report of $\mathrm{HO}$ after implantation of an interspinous/interlaminar dynamic device.

\section{Conclusion}

The reported case describes the formation of heterotopic ossification with the use of an interspinous/interlaminar Coflex device. These are several recent reported cases of delayed $\mathrm{HO}$ after dynamic stabilization systems, but none on interspinous/interlaminar dynamic devices. The effects of the dynamic stabilization systems on disc regeneration have recently been discussed. It is hoped that further studies will evaluate the potential relationship between dynamic stabilization and $\mathrm{HO}$, with or without other known associated risk factors. Above all, the case report's aim is to suggest the possibility of $\mathrm{HO}$ as a new complication of interspinous/interlaminar devices.

\section{Conflict of Interests}

The authors report no conflict of interests concerning the methods used in this study nor personal financial or institutional interest in any of the drugs, materials, or devices described in this article.

\section{References}

[1] A. F. Mavrogenis, P. N. Soucacos, and P. J. Papagelopoulos, "Heterotopic ossification revisited," Orthopedics, vol. 34, no. 3, p. 177, 2011.

[2] G. W. Wharton, "Heterotopic ossification," Clinical Orthopaedics and Related Research, vol. 112, pp. 142-149, 1975.

[3] D. F. Dalury and W. A. Jiranek, "The incidence of heterotopic ossification after total knee arthroplasty," Journal of Arthroplasty, vol. 19, no. 4, pp. 447-452, 2004.

[4] R. Iorio and W. L. Healy, "Heterotopic ossification after hip and knee arthroplasty: risk factors, prevention, and treatment," The Journal of the American Academy of Orthopaedic Surgeons, vol. 10, no. 6, pp. 409-416, 2002.

[5] M. Kocic, M. Lazovic, M. Mitkovic, and B. Djokic, "Clinical significance of the heterotopic ossification after total hip arthroplasty," Orthopedics, vol. 33, no. 1, p. 16, 2010.

[6] K. N. Nayak, B. Mulliken, C. H. Rorabeck, R. B. Bourne, and M. R. Woolfrey, "Prevalence of heterotopic ossification in cemented versus noncemented total hip joint replacement in patients with osteoarthrosis: a randomized clinical trial," Canadian Journal of Surgery, vol. 40, no. 5, pp. 368-374, 1997.

[7] A. J. G. Nollen and F. Q. M. P. Van Douveren, "Ectopic ossification in hip arthroplasty: a retrospective study of predisposing factors in 637 cases," Acta Orthopaedica Scandinavica, vol. 64, no. 2, pp. 185-187, 1993.

[8] K. R. B. S. Rama, P. A. Vendittoli, M. Ganapathi, R. Borgmann, A. Roy, and M. Lavigne, "Heterotopic ossification after surface replacement arthroplasty and total hip arthroplasty: a randomized study," Journal of Arthroplasty, vol. 24, no. 2, pp. 256-262, 2009.

[9] R. Schwarzkopf, R. M. Cohn, E. C. Skoda, M. Walsh, and F. Jaffe, "The predictive power of preoperative hip range of motion for the development of heterotopic ossification," Orthopedics, vol. 34, no. 3, p. 169, 2011.

[10] R. Bertagnoli, "Heterotopic ossification at the index level after Prodisc-C surgery: what is the clinical relevance?" The Spine Journal, vol. 8, no. 5, supplement, p. 123S, 2008.

[11] J. Chen, X. Wang, W. Bai, X. Shen, and W. Yuan, "Prevalence of heterotopic ossification after cervical total disc arthroplasty: a meta-analysis," European Spine Journal, vol. 21, pp. 674-680, 2012.

[12] V. Heidecke, W. Burkert, M. Brucke, and N. G. Rainov, "Intervertebral disc replacement for cervical degenerative disease-clinical results and functional outcome at two years in patients implanted with the Bryan cervical disc prosthesis," Acta Neurochirurgica, vol. 150, no. 5, pp. 453-459, 2008.

[13] M. Janssen, J. Goldstein, D. Murrey, and R. Delamarter, "Heterotopic ossification at the index level after Prodisc-C: what is the clinical significance?" The Spine Journal, vol. 7, no. 5, supplement, pp. 48S-49S, 2007.

[14] J. H. Lee, T. G. Jung, H. S. Kim, J. S. Jang, and S. H. Lee, "Analysis of the incidence and clinical effect of the heterotopic ossification in a single-level cervical artificial disc replacement," Spine Journal, vol. 10, no. 8, pp. 676-682, 2010.

[15] S. E. Lee, C. K. Chung, and T. A. Jahng, "Early development and progression of heterotopic ossification in cervical total disc replacement: clinical article," Journal of Neurosurgery, vol. 16, no. 1, pp. 31-36, 2012.

[16] C. Leung, A. T. Casey, J. Goffin et al., "Clinical significance of heterotopic ossification in cervical disc replacement: a prospective multicenter clinical trial," Neurosurgery, vol. 57, no. 4, pp. 759-763, 2005. 
[17] J. H. Park, S. C. Rhim, and S. W. Roh, "Mid-term followup of clinical and radiologic outcomes in cervical total disk replacement (Mobi-C): incidence of heterotopic ossification and risk factors," Journal of Spinal Disorders and Techniques. In press.

[18] P. Suchomel, L. Jurák, V. Beneš, R. Brabec, O. Bradáč, and S. Elgawhary, "Clinical results and development of heterotopic ossification in total cervical disc replacement during a 4-year follow-up," European Spine Journal, vol. 19, no. 2, pp. 307-315, 2010.

[19] J.-C. Wu, W.-C. Huang, T.-H. Tu et al., "Differences between soft-disc herniation and spondylosis in cervical arthroplasty: CT-documented heterotopic ossification with minimum 2 years of follow-up-clinical article," Journal of Neurosurgery, vol. 16, no. 2, pp. 163-171, 2012.

[20] S. Yi, K. N. Kim, M. S. Yang et al., "Difference in occurrence of heterotopic ossification according to prosthesis type in the cervical artificial disc replacement," Spine, vol. 35, no. 16, pp. 1556-1561, 2010.

[21] F. Hartmann, S. O. Dietz, S. Kuhn, H. Hely, P. M. Rommens, and E. Gercek, "Biomechanical comparison of an interspinous device and a rigid stabilization on lumbar adjacent segment range of motion," Acta Chirurgiae Orthopaedicae et Traumatologiae Cechoslovaca, vol. 78, no. 5, pp. 404-409, 2011.

[22] B. Y. Cho, J. Murovic, K. W. Park, and J. Park, "Lumbar disc rehydration postimplantation of a posterior dynamic stabilization system: case report," Journal of Neurosurgery, vol. 13, no. 5, pp. 576-580, 2010.

[23] C. M. Bono and A. R. Vaccaro, "Interspinous process devices in the lumbar spine," Journal of Spinal Disorders and Techniques, vol. 20, no. 3, pp. 255-261, 2007.

[24] F. Villarejo, F. Carceller, A. G. de la Riva, and M. Budke, "Experience with coflex interspinous implant," Acta Neurochirurgica Supplement, vol. 108, pp. 171-175, 2011.

[25] D. H. Kim, M. Tantorski, J. Shaw et al., "Occult spinous process fractures associated with interspinous process spacers," Spine, vol. 36, no. 16, pp. E1080-E1085, 2011.

[26] D. H. Kim and T. J. Albert, "Interspinous process spacers," Journal of the American Academy of Orthopaedic Surgeons, vol. 15, no. 4, pp. 200-207, 2007.

[27] D. S. Kong, E. S. Kim, and W. Eoh, "One-year outcome evaluation after interspinous implantation for degenerative spinal stenosis with segmental instability," Journal of Korean Medical Science, vol. 22, no. 2, pp. 330-335, 2007.

[28] C. Schizas, G. Kulik, and V. Kosmopoulos, "Disc degeneration: current surgical options," European Cells \& Materials, vol. 20, pp. 306-315, 2010.

[29] K. J. Tsai, H. Murakami, G. L. Lowery, and W. C. Hutton, "A biomechanical evaluation of an interspinous device (Coflex) used to stabilize the lumbar spine," Journal of Surgical Orthopaedic Advances, vol. 15, no. 3, pp. 167-172, 2006.

[30] E. J. Kerr, A. Jawahar, S. Kay, D. A. Cavanaugh, and P. D. Nunley, "Implant design may influence delayed heterotopic ossification after total disk arthroplasty in lumbar spine," Surgical Neurology, vol. 72, no. 6, pp. 747-751, 2009.

[31] S. J. Park, K. J. Kang, S. K. Shin, S. S. Chung, and C. S. Lee, "Heterotopic ossification following lumbar total disc replacement," International Orthopaedics, vol. 35, pp. 1197 1201, 2011.

[32] C. Mehren, P. Suchomel, F. Grochulla et al., "Heterotopic ossification in total cervical artificial disc replacement," Spine, vol. 31, no. 24, pp. 2802-2806, 2006.
[33] P. J. Tortolani, B. W. Cunningham, P. C. McAfee, G. A. Holsapple, and K. A. Adams, "Prevalence of heterotopic ossification following total disc replacement: a prospective, randomized study of two hundred and seventy-six patients," Journal of Bone and Joint Surgery —Series A, vol. 89, no. 1, pp. 82-88, 2007.

[34] C. L. Anderson and M. C. Whitaker, "Heterotopic ossification associated with recombinant human bone morphogenetic protein-2 (Infuse) in posterolateral lumbar spine fusion: a case report," Spine, vol. 37, no. 8, pp. E502-E506, 2012.

[35] R. S. Brower and N. M. Vickrov, "A case of psoas ossification from the use of BMP-2 for posterolateral fusion at L4-L5," Spine (Phila Pa 1976), vol. 33, pp. E653-E655, 2008.

[36] C. A. Cipriano, S. G. Pill, and M. A. Keenan, "Heterotopic ossification following traumatic brain injury and spinal cord injury," Journal of the American Academy of Orthopaedic Surgeons, vol. 17, no. 11, pp. 689-697, 2009.

[37] T. A. Balboni, R. Gobezie, and H. J. Mamon, "Heterotopic ossification: pathophysiology, clinical features, and the role of radiotherapy for prophylaxis," International Journal of Radiation Oncology Biology Physics, vol. 65, no. 5, pp. 12891299, 2006.

[38] D. Shehab, A. H. Elgazzar, and B. D. Collier, "Heterotopic ossification," Journal of Nuclear Medicine, vol. 43, no. 3, pp. 346-353, 2002.

[39] P. C. McAfee, B. W. Cunningham, J. Devine, E. Williams, and J. Yu-Yahiro, "Classification of heterotopic ossification (HO) in artificial disk replacement," Journal of Spinal Disorders and Techniques, vol. 16, no. 4, pp. 384-389, 2003.

[40] A. F. Brooker, J. W. Bowerman, R. A. Robinson, and L. H. Riley, "Ectopic ossification following total hip replacement. Incidence and a method of classification," Journal of Bone and Joint Surgery-Series A, vol. 55, no. 8, pp. 1629-1632, 1973.

[41] F. J. Andreu Martínez, J. M. Martínez Mateu, and V. Tormo Ferrero, "The role of radiotherapy for prevention of heterotopic ossification after major hip surgery," Clinical and Translational Oncology, vol. 9, no. 1, pp. 28-31, 2007.

[42] R. J. Macfarlane, B. H. Ng, Z. Gamie et al., "Pharmacological treatment of heterotopic ossification following hip and acetabular surgery," Expert Opinion on Pharmacotherapy, vol. 9, no. 5, pp. 767-786, 2008.

[43] G. I. Vasileiadis, Mavrogenis, Babis, Papagelopoulos, Vlasis, and Sioutis, "COX-2 inhibitors for the prevention of heterotopic ossification after THA," Orthopedics, vol. 34, no. 6, p. 467, 2011.

[44] C. Zeckey, F. Hildebrand, M. Frink, and C. Krettek, "Heterotopic ossifications following implant surgery-epidemiology, therapeutical approaches and current concepts," Seminars in Immunopathology, vol. 33, no. 3, pp. 273-286, 2011. 


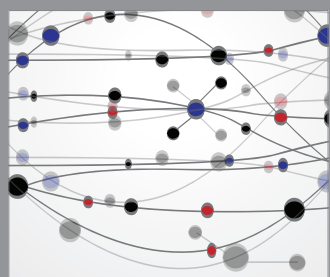

The Scientific World Journal
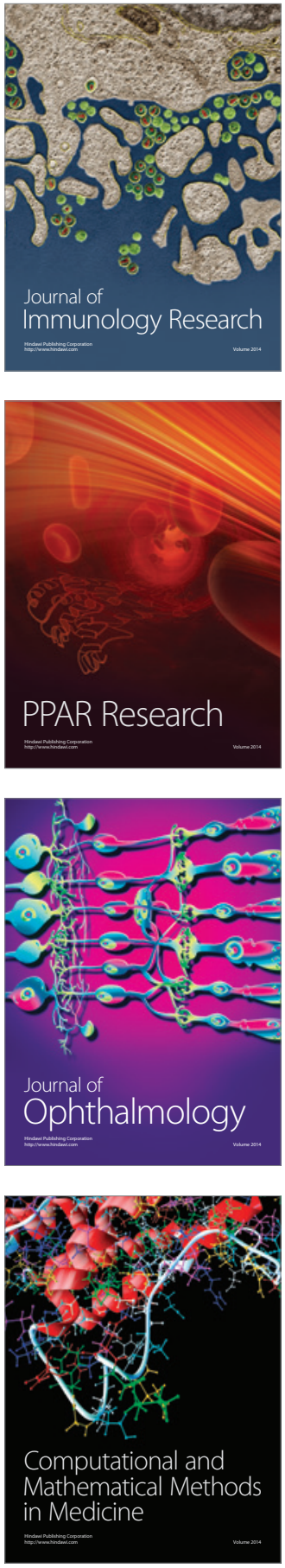

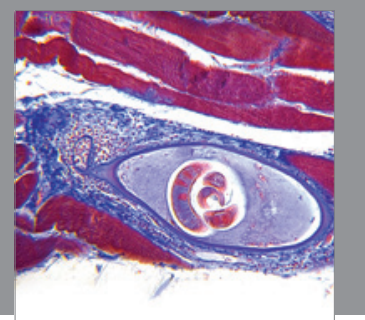

Gastroenterology

Research and Practice
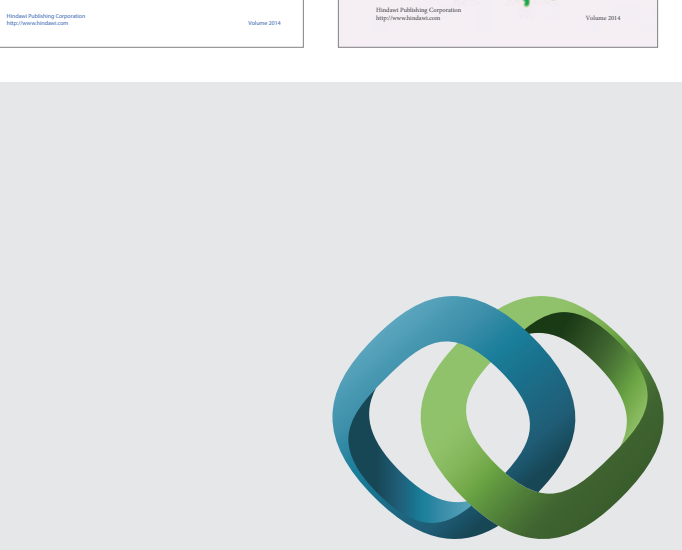

\section{Hindawi}

Submit your manuscripts at

http://www.hindawi.com
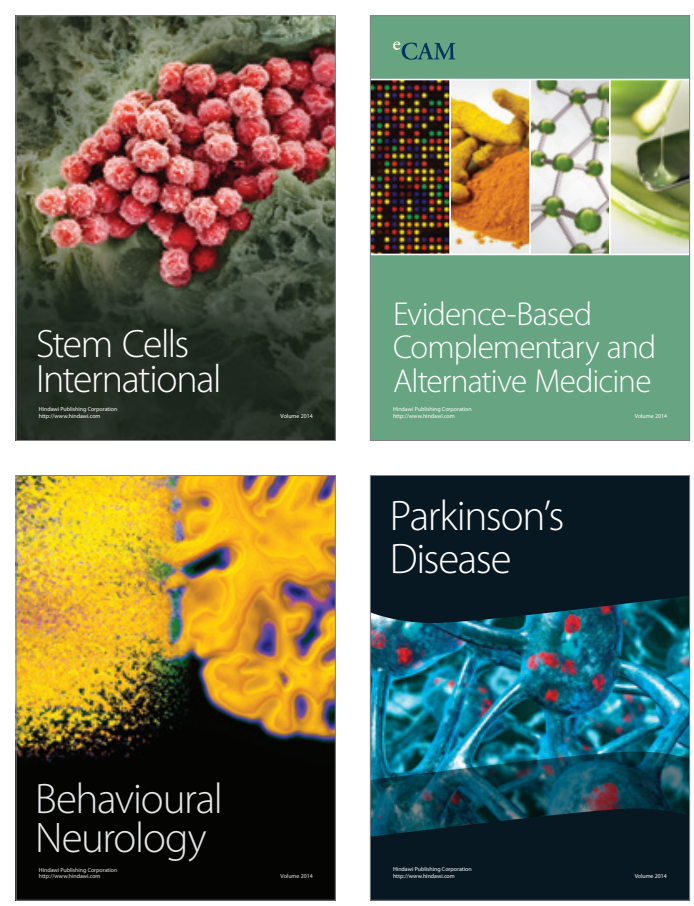

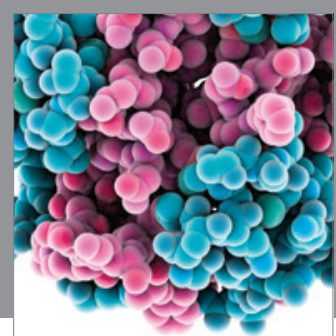

Journal of
Diabetes Research

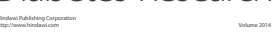

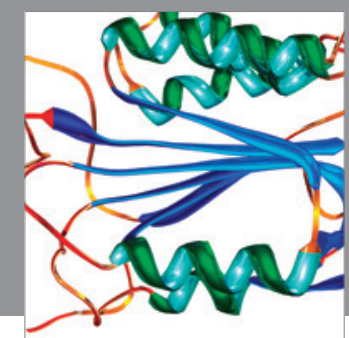

Disease Markers
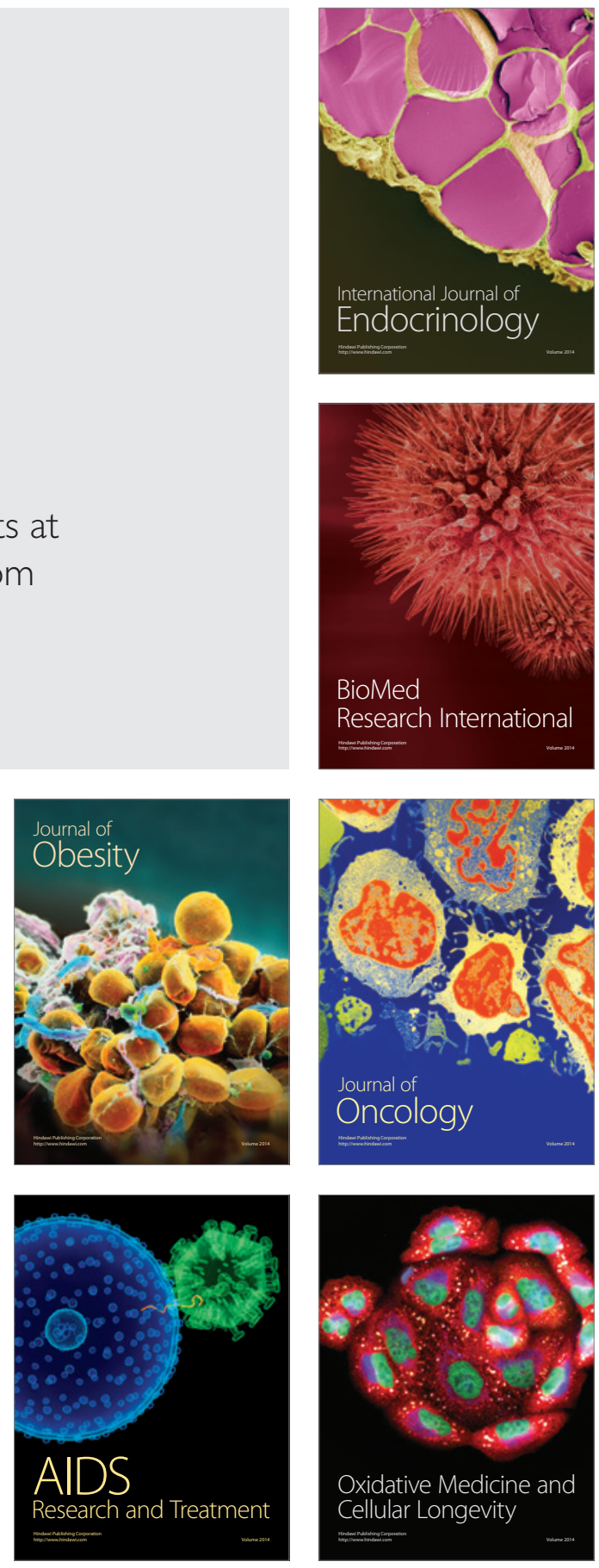